\title{
BMJ Open Diagnosis and treatment of chlamydia and gonorrhoea in general practice in England 2000-2011: a population-based study using data from the UK Clinical Practice Research Datalink
}

\author{
Sally Wetten, ${ }^{1}$ Hamish Mohammed, ${ }^{1}$ Mandy Yung, ${ }^{1}$ Catherine $\mathrm{H}$ Mercer, ${ }^{2}$ \\ Jackie A Cassell, ${ }^{3,4}$ Gwenda Hughes ${ }^{1}$
}

To cite: Wetten S,

Mohammed $\mathrm{H}$, Yung $\mathrm{M}$, et al. Diagnosis and treatment of chlamydia and gonorrhoea in general practice in England 2000-2011: a populationbased study using data from the UK Clinical Practice Research Datalink. BMJ Open 2015;5:e007776.

doi:10.1136/bmjopen-2015007776

- Prepublication history and additional material is available. To view please visit the journal (http://dx.doi.org/ 10.1136/bmjopen-2015007776).

SW and $\mathrm{HM}$ are Joint first authors.

Received 26 January 2015 Revised 20 February 2015 Accepted 27 February 2015

CrossMark

For numbered affiliations see end of article.

Correspondence to: Dr Catherine H Mercer; c.mercer@ucl.ac.uk

\section{ABSTRACT}

Objectives: To determine the relative contribution of general practices (GPs) to the diagnosis of chlamydia and gonorrhoea in England and whether treatment complied with national guidelines.

Design: Analysis of longitudinal electronic health records in the Clinical Practice Research Datalink (CPRD) and national sexually transmitted infection (STI) surveillance databases, England, 2000-2011.

Setting: GPs, and community and specialist STI services. Participants: Patients diagnosed with chlamydia $(n=1386$ 169) and gonorrhoea ( $n=232$ 720) at CPRD GPs, and community and specialist STI Services from 2000-2011.

Main outcome measures: Numbers and rates of chlamydia and gonorrhoea diagnoses; percentages of patients diagnosed by GPs relative to other services; percentage of GP patients treated and antimicrobials used; percentage of GP patients referred.

Results: The diagnosis rate $(95 \% \mathrm{Cl})$ per 100000 population of chlamydia in GP increased from 22.8 (22.4-23.2) in 2000 to 29.3 (28.8-29.7) in 2011 $(p<0.001)$, while the proportion treated increased from $59.5 \%$ to $78.4 \%$ ( $p=0.001)$. Over $90 \%$ were prescribed a recommended antimicrobial. Over the same period, the diagnosis rate $(95 \% \mathrm{Cl})$ per 100000 population of gonorrhoea in GP ranged between 3.2 (3-3.3) and $2.4(2.2-2.5 ; p=0.607)$, and the proportion treated ranged between $32.7 \%$ and $53.6 \%$ ( $p=0.262$ ). Despite being discontinued as a recommended therapy for gonorrhoea in 2005 , ciprofloxacin accounted for $42 \%$ of prescriptions in 2007 and $20 \%$ in 2011. Over the study period, GPs diagnosed between $9 \%$ and $16 \%$ of chlamydia cases and between $6 \%$ and $9 \%$ of gonorrhoea cases in England.

Conclusions: GP makes an important contribution to the diagnosis and treatment of bacterial STIs in England. While most patients diagnosed with chlamydia were managed appropriately, many of those treated for gonorrhoea received antimicrobials no longer recommended for use. Given the global threat of antimicrobial resistance, GPs should remain abreast of national treatment guidelines and alert to treatment failure in their patients.

\section{Strengths and limitations of this study}

- This study determined the proportional contribution and trend in chlamydia and gonorrhoea diagnoses from general practices (GPS) relative to other services, and whether these infections were treated appropriately.

- Some double counting of diagnoses of patients referred to specialist sexually transmitted infection services is likely.

- Diagnoses of chlamydia and gonorrhoea made outside GP, and made outside community and specialist services that routinely report to national surveillance systems, could not be included in our analysis, but it is likely that the great majority of diagnoses were captured.

- This study provides more complete estimates of the burden of chlamydia and gonorrhoea diagnoses in England.

- Most patients diagnosed with chlamydia are managed appropriately; however, many diagnosed with gonorrhoea were treated with antimicrobials no longer recommended for use.

\section{INTRODUCTION}

Chlamydia and gonorrhoea are the two most commonly diagnosed bacterial sexually transmitted infections (STIs) in the UK, with 237675 and 28594 diagnoses, respectively, reported in 2012. ${ }^{1}$ Although gonorrhoea is less prevalent than chlamydia $(<0.1 \%$ in women and men aged $16-44$ years, vs $1.5 \%$ and $1.1 \%$, respectively, in a recent national probability survey), ${ }^{2}$ it can be common in areas with high concentrations of 'core group' populations, such as men who have sex with men and persons of black Caribbean ethnicity. ${ }^{3}{ }^{4}$ Infection with these STIs is usually easily treated with antimicrobials but, in the case of gonorrhoea, is complicated by the ability of the infecting bacterium, Neisseria gonorrhoeae, to develop 
resistance rapidly. ${ }^{5}$ Chlamydial and gonorrhoeal infection in women is often asymptomatic and may remain undiagnosed. ${ }^{7}$ Untreated or inadequately treated infection can lead to complications such as chronic pelvic pain, pelvic inflammatory disease, ectopic pregnancy and infertility. ${ }^{8}$

During the 1990s, the majority of STI diagnoses in England were made in specialist genitourinary medicine (GUM) services. ${ }^{9}$ Since then, primary and community care services have played an increasingly important role in the diagnosis of STIs, especially of chlamydia, following the introduction of the National Chlamydia Screening Programme (NCSP) in 2003. ${ }^{10-13}$ Of those who do attend GUM clinics, up to $40 \%$ may have initially presented at their general practice (GP). ${ }^{14-16}$ However, while screening of asymptomatic infections and testing of uncomplicated symptomatic infections is appropriate in non-specialist services, including GPs, referral to specialist providers for further management and partner notification may sometimes be required to ensure national standards of care are met. ${ }^{17}{ }^{18}$ In particular, as gonorrhoea can rapidly develop resistance to front-line therapies, those diagnosed should be referred to specialist providers for treatment, test of cure and to perform culture, in order to avoid inadequate treatment and the dissemination of resistant or less susceptible strains. ${ }^{17}$

Despite these significant changes in the delivery of STI services, there is limited recent evidence on the extent to which STIs are diagnosed, treated and managed in GP, and on the appropriateness and quality of care received there. ${ }^{9}{ }^{19}$ In this study, we analysed data from the Clinical Practice Research Datalink (CPRD) and national STI surveillance databases to estimate the relative contribution of GP to the diagnosis and treatment of chlamydia and gonorrhoea in England between 2000 and 2011. For those cases diagnosed in GP, we investigated whether prescriptions to treat chlamydial and gonococcal infections were issued and, if so, whether these met standards specified in respective national treatment guidelines.

\section{METHODS}

Study populations and period

General practice

The CPRD is run by the Medicines and Healthcare Products Regulatory Agency (MHRA) and collects anonymised patient-level data on all medical, prescription, investigation/test, immunisation and referral records of registered patients in a sample of GPs in the UK. ${ }^{20}$ All practices use a standard software system to submit data to the CPRD, which has been extensively used and validated for public health, epidemiological and pharmacoepidemiological research, as described elsewhere. ${ }^{21-23}$ The CPRD has also been shown to be demographically representative of the UK population, with a national coverage of $6.4 \%$ of the population in England, $5.1 \%$ in Wales, $2.8 \%$ in Scotland and $5.8 \%$ in Northern Ireland. ${ }^{24}$
All registered patients in CPRD practices in England aged 12-90 years between 1 January 2000 and 31 December 2011 were included in the analysis. Any records not classified as 'up-to-standard' at practice or patient level were excluded. ${ }^{20}$ This is a measure based on an assessment of completeness, continuity and plausibility of data recording in key areas as regulated by the CPRD.

\section{GUM clinics}

Data from patients attending GUM clinics in England between 1 January 2000 and 31 December 2011 were extracted from national surveillance databases held and managed by Public Health England (PHE): the Korner Code-60 (KC60) statistical return (2000-2008) and the GUM clinic activity dataset (GUMCAD; 2009 onwards). ${ }^{25}$ Form KC60 was a paper-based aggregated statistical return while GUMCAD collects electronic, disaggregated, attendance-level data. Reporting of GUM clinic statistical returns is mandatory and all GUM clinics in England (209 clinics in 2011) report data every calendar quarter.

\section{Other sexual health services providing chlamydia testing}

Data on patients attending for chlamydia testing outside GUM clinics as part of the NCSP between 1 January 2008 and 31 December 2011 were extracted from aggregated data returns from laboratories reported to PHE. ${ }^{26}$

\section{Diagnoses of chlamydia and gonorrhoea by service setting}

For patients attending GP, attendances for chlamydia and gonorrhoea were identified using a predefined selection of Read codes (see web tables 1 and 2) included in all medical, referral and test records. Read codes are assigned at each GP consultation including any follow-up attendances for a single disease episode. In order to determine numbers of individual diagnostic episodes, we assumed an episode length of 42 days during which duplicate codes were excluded. This was consistent with previously validated approaches for estimating episode length. ${ }^{19} 27$

Numbers of chlamydia and gonorrhoea diagnoses made at GUM clinics were recorded and identified, using appropriate KC60, and sexual health and HIV activity property type (SHHAPT) diagnostic codes. ${ }^{25}$ For attendance-level data reported through GUMCAD (ie, since 2009), the length of individual diagnostic episodes was defined as for CPRD data (see above). Numbers of chlamydia diagnoses made by the NCSP were directly recorded on aggregated NCSP returns. Chlamydia diagnoses made by GPs through the NCSP were excluded to avoid double counting.

\section{Prescribing in GP}

In CPRD, prescriptions and medical records are not linked, leading to some ambiguity about the indication for which a particular prescription is issued, especially for broad-spectrum antibiotics commonly used to treat bacterial STIs. For example, prescriptions may be issued 


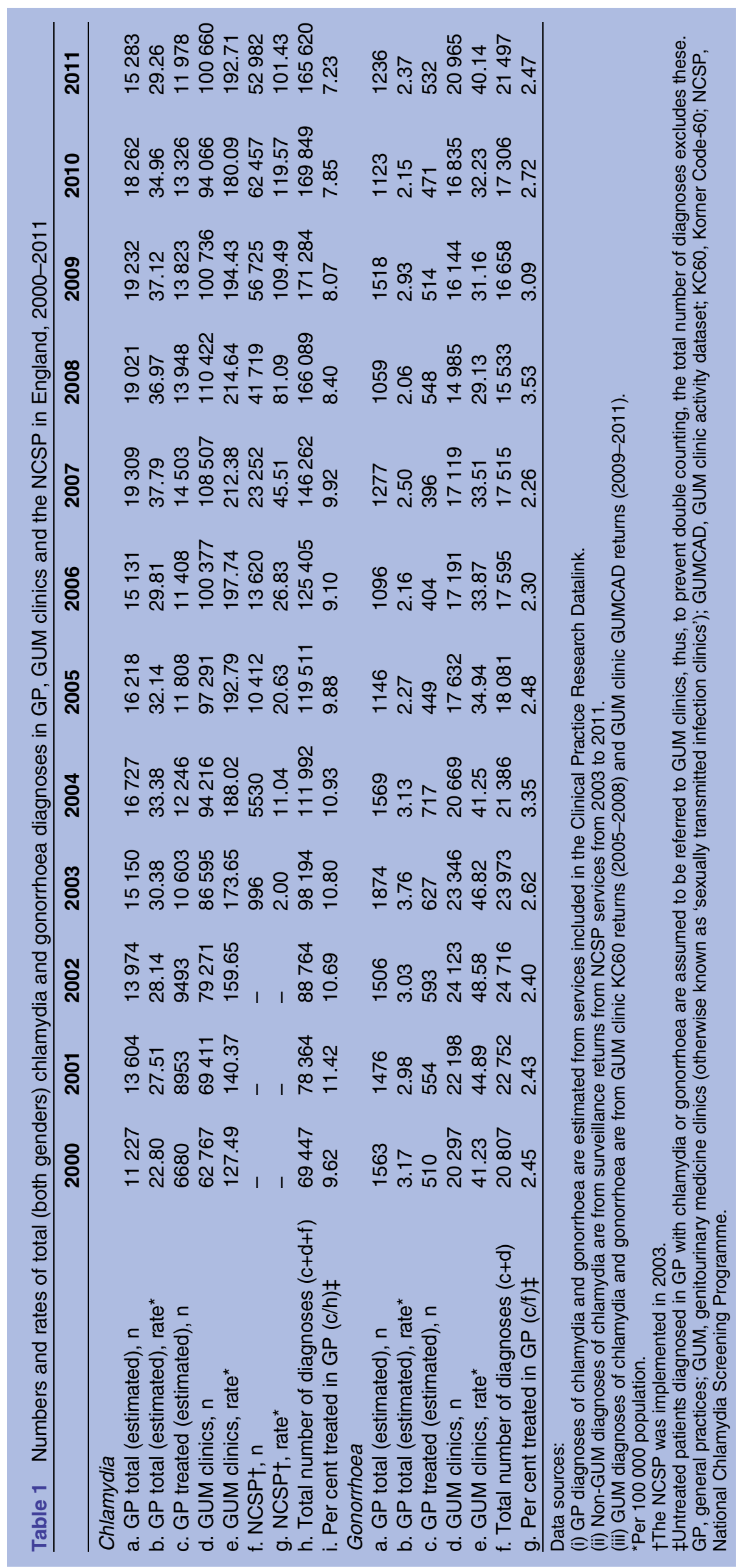


Table 2 Percentage of chlamydia and gonorrhoea episodes by antimicrobial prescribed among general practices included in the Clinical Practice Research Datalink in England, by year, 2000-2011

\begin{tabular}{|c|c|c|c|c|c|c|c|c|c|c|c|c|}
\hline & 2000 & 2001 & 2002 & 2003 & 2004 & 2005 & 2006 & 2007 & 2008 & 2009 & 2010 & 2011 \\
\hline Chlamydia $(M)$ & 716 & 925 & 994 & 1088 & 1219 & 1196 & 1145 & 1471 & 1446 & 1453 & 1374 & 1130 \\
\hline Azithromycin* & 9 & 11 & 14 & 19 & 21 & 23 & 25 & 32 & 38 & 42 & 49 & 55 \\
\hline Doxycycline* & 38 & 46 & 44 & 42 & 44 & 42 & 44 & 37 & 30 & 26 & 19 & 18 \\
\hline Erythromycin* & 7 & 4 & 5 & 4 & 4 & 4 & 4 & 3 & 4 & 2 & 3 & 3 \\
\hline Ofloxacin* & 1 & 1 & 1 & 1 & 2 & 2 & 1 & 1 & 1 & 1 & 1 & 1 \\
\hline Other macrolides & 1 & 0 & 0 & 0 & 0 & 0 & 0 & 1 & 0 & 0 & 0 & 0 \\
\hline Other quinolones & 1 & 0 & 1 & 0 & 0 & 0 & 0 & 0 & 0 & 0 & 0 & 0 \\
\hline Other tetracyclines & 1 & 1 & 1 & 1 & 1 & 1 & 1 & 0 & 0 & 0 & 0 & 0 \\
\hline Penicillins & 2 & 2 & 1 & 2 & 1 & 0 & 1 & 1 & 1 & 1 & 1 & 1 \\
\hline Not treated & 41 & 34 & 32 & 30 & 27 & 27 & 25 & 25 & 27 & 28 & 27 & 22 \\
\hline Gonorrhoea $(N)$ & 101 & 103 & 109 & 135 & 118 & 87 & 85 & 101 & 81 & 117 & 86 & 93 \\
\hline Cephalosporins† & 3 & 5 & 4 & 1 & 2 & 6 & 12 & 6 & 26 & 14 & 13 & 16 \\
\hline Macrolidesł & 3 & 1 & 4 & 1 & 2 & 3 & 6 & 4 & 4 & 3 & 2 & 8 \\
\hline Quinolones§ & 11 & 20 & 19 & 19 & 30 & 22 & 15 & 15 & 17 & 10 & 16 & 9 \\
\hline Tetracyclines & 5 & 9 & 2 & 7 & 4 & 2 & 0 & 3 & 2 & 3 & 2 & 4 \\
\hline Penicillins & 11 & 3 & 11 & 6 & 8 & 6 & 4 & 3 & 2 & 3 & 8 & 6 \\
\hline Not treated & 67 & 62 & 61 & 67 & 54 & 61 & 64 & 69 & 48 & 67 & 58 & 57 \\
\hline
\end{tabular}

Shaded areas represent periods when selected antimicrobial was not recommended in national treatment guidelines.

National Treatment Guidelines. ${ }^{29-31}$

${ }^{*}$ Recommended antimicrobial.

†Cefixime and ceftriaxone comprised $79 \%$ of the cephalosporins prescribed and cefixime was the recommended therapy from 2005 to 2011.

$\ddagger$ Azithromycin, with ceftriaxone, was recommended for treatment from 2011.

§Ciprofloxacin comprised 92\% of the quinolones prescribed and was the recommended therapy until 2004.

prior to test results being available and entry of a confirmed diagnosis in the electronic patient record, or for a concurrent indication unrelated to the STI.

We conducted a sensitivity analysis on a sample of chlamydia and gonorrhoea records in CPRD from 1 January 2003 to 30 June 2008 to determine the optimum timeframe for linking prescriptions with diagnosis codes. Only recommended treatments during the study period were used in the sensitivity analysis (doxycycline, azithromycin, erythromycin and ofloxacin for chlamydia, and cephalosporins and ciprofloxacin (until 2004) for gonorrhoea). Prescriptions at 0-day, 7-day, 14-day and 30-day intervals on either side of a chlamydia or gonorrhoea diagnostic code were investigated for the presence of coindications (see web figure). A 14-day interval provided the maximum proportion of treated STI episodes during which there were no coindications, and was considered optimum. Compared with including prescriptions issued only on the date of diagnosis, this algorithm increased the number of episodes treated by $12 \%$ for chlamydia and 3\% for gonorrhoea. The sensitivity of this method was $97.9 \%$ and $99.1 \%$ for chlamydia and gonorrhoea, respectively.

To investigate actual prescribing practice, all drugs in the respective drug classes were included, that is, tetracyclines, macrolides, penicillins, cephalosporins and fluoroquinolones. Chlamydia and gonorrhoea episodes were classified as treated if (1) there were no alternative indications found within the 14-day interval, or (2) alternative indications were found but the prescription was issued on the same date as the STI diagnosis. If more than one relevant prescription was issued during an episode, the prescription that was recommended or issued closest to the diagnosis date was preferred. Any unusual prescriptions found using the algorithm were examined manually.

\section{Patient referrals from GP}

In CPRD, information on patient referrals can be stored as Read codes in medical and investigation/test records, in specific referral to specialty records, or in unstructured format in the free text field. A patient was defined as having been referred for further management if any structured record indicating a referral was found within the 42-day period of the STI episode. We did not have access to the free text records, and assumed that most episodes without a treatment or referral code had likely been informally referred. ${ }^{19}$

\section{Count and rate estimates for England}

Numbers of diagnostic episodes of chlamydia and gonorrhoea within the CPRD population were calculated. Overall and annual age-standardised and genderstandardised diagnosis counts and rates (per 100000 population) with $95 \%$ CIs were then estimated for all GPs in England, using English population estimates. ${ }^{28}$ Diagnosis counts and rates of chlamydia and gonorrhoea in GUM clinics and, for chlamydia, through the NCSP (excluding GP), were calculated.

Population count and rate estimates in GP were then expressed as a percentage of total diagnoses and rates in England. We assumed that all diagnoses made in GP represented the first patient attendance for care, and that all non-treated episodes had been referred to a specialist 
service where a diagnosis would have been recorded and treated. To avoid double counting when calculating the percentage of all diagnoses that were made in GP, all nontreated episodes were therefore excluded from the denominator. The percentage of all episodes that were treated in GP was calculated in the same way. Tests for linear trend were performed, and all $\mathrm{p}$ values less than $5 \%$ were considered statistically significant. Statistical analyses were performed in Microsoft Excel 2010 (Microsoft Corporation, Redmond, Washington, USA) and Stata V.13.1 (StataCorp LA, College Station, Texas, USA).

\section{Ethic statement}

All GP practices included in the CPRD require consent from their patients for their anonymised data to be included in the data set. This protocol to examine STI trends in CPRD patients was approved by the Independent Scientific Advisory Committee of the CPRD. As GUMCAD and the NCSP are routine public health surveillance activities, no specific consent was required from those patients whose pseudoanonymised (age and limited demographic data without any patient identifiable information) data were considered in this study. PHE has permission to handle data obtained from GUMCAD and the NCSP under section 251 of the UK National Health Service Act of 2006 (previously section 60 of the Health and Social Care Act of 2001), which was renewed annually by the ethics and confidentiality committee of the National Information Governance Board until 2013. Since then, the power of approval of public health surveillance activity has been granted directly to PHE.
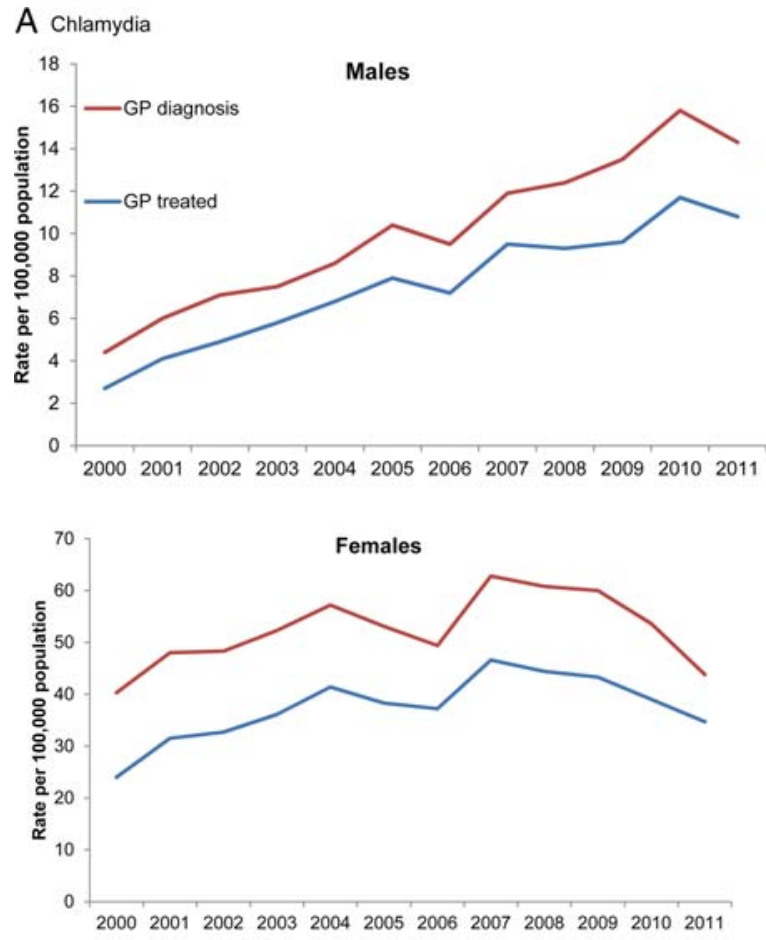

Note: Different scales used on the $y$-axis for each graph.

Figure 1 Rates of $(A)$ chlamydia and $(B)$ gonorrhoea diagnosed and treated in general practice (GP) clinics included in the Clinical Practice Research Datalink in England, by gender, 2000-2011.

\section{RESULTS}

\section{Chlamydia}

Numbers and rates of diagnoses in GP and other healthcare settings

Estimated and actual numbers and rates of chlamydia diagnoses made in GP, the NCSP and GUM clinics between 2000 and 2011 are presented in table 1 and web table 3. During the study period, the estimated rate (95\% CI) per 100000 of chlamydia diagnosis in GP increased from 22.8 (22.4-23.2) in 2000 to 29.3 (28.8$29.7)$ in $2011(\mathrm{p}=0.034)$. In $2000,90.5 \%$ of episodes in GP were diagnosed in females $(40.3 / 100000,95 \%$ CI 39.5 to 41.1 ) and this decreased to $76 \%$ in 2011 (43.8/ $100000,95 \%$ CI 43.1 to 44.7 ; $\mathrm{p}$ value for trend in proportions: 0.001 ; figure 1 ). The diagnosis rate in males increased from 4.4 (4.2-4.7) in 2000 to 14.3 (13.8-14.7) in 2011 (figure 1). During the same period, rates of diagnoses made in GUM clinics rose from 127.5 to 192.7 per $100000 \quad(\mathrm{p}=0.025)$, and between 2003 and 2011, rates of diagnoses made by the NCSP rose from 2.0 to 101.4 per $100000(\mathrm{p}=0.007)$. The percentage $(95 \% \mathrm{CI})$ of chlamydia diagnoses made in GP relative to other settings decreased from $16.2 \%(15.9-16.4 \%)$ in 2000 to $9.2 \%(9.1-9.4 \%)$ in $2011(\mathrm{p}=0.001)$.

\section{Prescribing practice in GP}

A total of 10196 episodes of chlamydia were defined as treated in the CPRD population (after removing 46 following manual review). The percentage $(95 \% \mathrm{CI})$ of episodes treated increased from $59.5 \%(55.8-63.1 \%)$ in 2000 to $78.5 \%(76.0-80.9 \%)$ in 2011 ( $p=0.012$; table 2$)$. Each
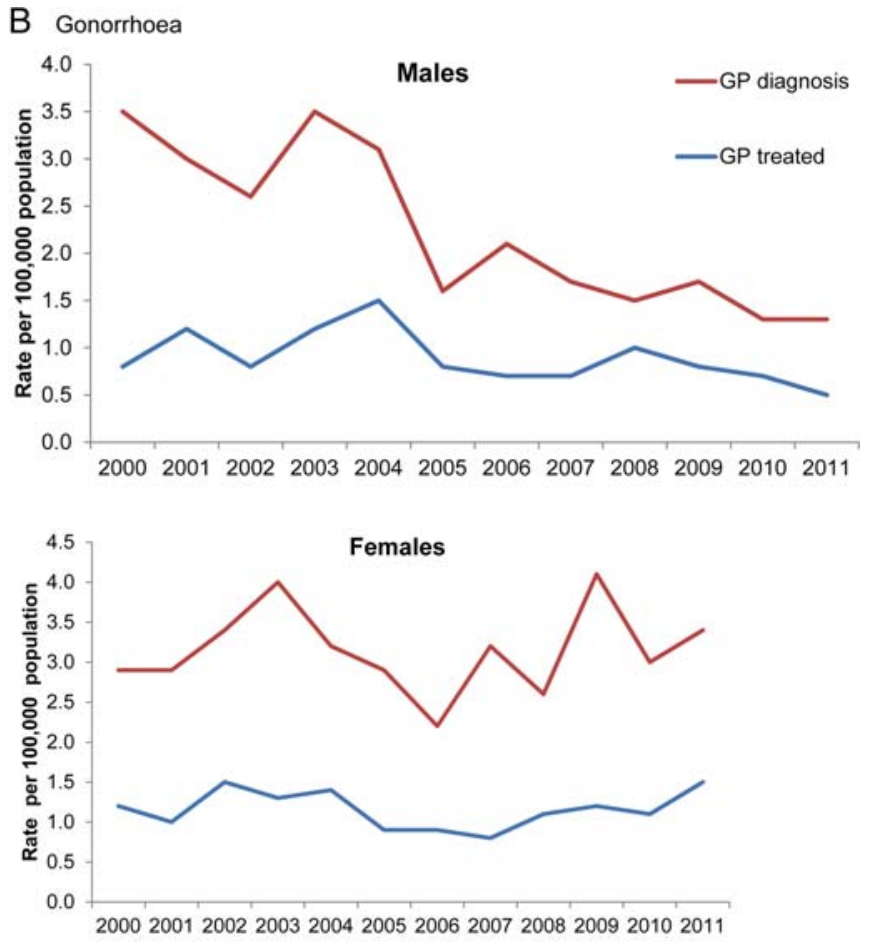
year, over $90 \%$ of treated episodes were given a BASHH (British Association for Sexual Health and HIV) recommended regimen (table 2). ${ }^{29}$ Between 2000 and 2011, use of azithromycin increased steadily and accounted for $70.6 \%$ of treatments in 2011, while doxycycline use declined from $63.6 \%$ to $23.1 \%$ ( $\mathrm{p}=0.001)$. A small number of non-recommended regimens were identified, although this decreased from $7.0 \%$ to $1.5 \%$ of treatments from 2000 to 2011 ( $p=0.002)$. Clarithromycin accounted for all other macrolides and ciprofloxacin for all fluoroquinolones prescribed (there was no evidence of concomitant gonorrhoea diagnoses). Amoxicillin can be prescribed in pregnancy and accounted for $58 \%$ of episodes prescribed penicillins. Of these patients, $18 \%$ were pregnant, $33 \%$ were on contraception, $35 \%$ had no evidence of pregnancy and $14 \%$ were male.

\section{Referrals}

Only $3 \%$ of all chlamydia episodes had a referral recorded.

\section{Gonorrhoea}

\section{Numbers and rates of diagnoses in GP and GUM clinics}

Estimated and actual numbers and rates of gonorrhoea diagnoses made in GP and GUM clinics between 2000 and 2011 are presented in table 1 . Between 2000 and 2011, the estimated rate (95\% CI) per 100000 population of gonorrhoea diagnosis in GP fell from 3.2 (3-3.3) in 2000 to $2.4(2.2-2.5)$ in $2011(\mathrm{p}=0.018)$ and the percentage of GP diagnoses in women rose from $46.5 \%$ to $72.3 \%$ ( $\mathrm{p}=0.003$; table 1 , figure 1 ). During the same period, rates of diagnoses per 100000 population made in GUM clinics decreased overall, having fluctuated from 41.2 in 2000 to 44.9 in 2001, fallen to 29.1 in 2008 then increased to 40.1 in 2001 ( $p=0.014)$. The percentage $(95 \% \mathrm{CI})$ of gonorrhoea diagnoses made in GP relative to GUM clinics fluctuated between $7.5 \%(7.2-7.9 \%)$ in $2000,9.1 \%(8.7-9.6 \%)$ in 2009 and $5.7 \%(5.4-6.1 \%)$ in $2011(\mathrm{p}=0.607)$.

\section{Prescribing practice in GP}

A total of 467 gonorrhoea episodes were defined as treated in the CPRD population (after removing 44 following manual review). The percentage (95\% CI) of episodes treated fluctuated over the 12-year period, increasing from $32.7 \%(23.7-42.7 \%)$ in 2000 to $43.0 \%(32.8-53.7 \%)$ in 2011 , with a peak of $51.9 \%(40.5-63.1 \%)$ in 2008 $(\mathrm{p}=0.271$; table 2$)$. Over the study period, an average of $40 \%$ received a recommended regimen each year. ${ }^{30} 31$ Ciprofloxacin (92\% of fluoroquinolones prescribed) was the most commonly prescribed antibiotic $(41 \%$ of treated episodes) and continued to be used after the change in national treatment guidelines favouring cephalosporins in $2005:^{31}$ it comprised $42 \%$ of prescriptions in 2006 and 2007, decreasing to $20 \%$ in 2011 (table 2). Cefixime and ceftriaxone (79\% of cephalosporins prescribed) were increasingly prescribed from 2005 and were the most commonly prescribed antibiotics $(35 \%)$ in 2011.
A high proportion of non-recommended regimens were prescribed including doxycycline, azithromycin and other macrolides (erythromycin, clarithromycin), and penicillin; this proportion fluctuated, decreasing from $67 \%$ in 2000 to $39 \%$ in 2004 , after which it increased to $65 \%$ in 2011 ( $\mathrm{p}=0.304)$. Amoxycillin and ampicillin $(42 \%$ of penicillins prescribed) accounted for 90\% (28) of these episodes, of which patients were either male (19\%) or females with no evidence of pregnancy in their record $(32 \%)$ or on contraception $(39 \%)$. Over half $(53 \%)$ of prescriptions for other penicillins were for gonococcal cellulitis.

\section{Referrals}

Of the 1216 gonorrhoea episodes, 57 had a referral record, $29(51 \%)$ of which had also been prescribed an antimicrobial. An estimated 771 (63\%) episodes were referred to GUM.

\section{DISCUSSION}

We present a comprehensive analysis of the management of chlamydia and gonorrhoea in GP in England since the turn of the century, against a backdrop of unprecedented changes in sexual health service provision. We show that GPs make an important contribution to the diagnosis and management of these STIs; however, while rates of chlamydia diagnosed in GP have increased, especially among males, those of gonorrhoea have been stable or declined. Prescribing practice has also varied markedly and, although a greater proportion of GP patients diagnosed with either infection are now being treated there, there is evidence that treatment of a significant proportion of gonorrhoea cases used antimicrobials that were no longer recommended in the national guideline.

Despite the increasing chlamydia diagnosis rates in GP, the proportional contribution from GP to the total number of chlamydia diagnoses made in England has decreased over time to about $9 \%$, coinciding with the scaling up of the NCSP from 2003 to 2008. There are now over 200000 chlamydia diagnoses made each year in England and over half of these occur in 'communitybased' sexual health services such as contraception and sexual health clinics, as well as GPs. ${ }^{32}$ The primary aim of the NCSP is to improve detection and treatment of chlamydial infection through increased testing of asymptomatic infection, and achieving a chlamydia diagnosis rate of 2300/100 000 in 15-24-year-olds is now an indicator in the Public Health Outcomes Framework (PHOF). ${ }^{33}$ It seems likely that increased chlamydia diagnosis rates in GP reflect the overall drive to improve chlamydia testing coverage that has occurred in response to the NCSP.

Gonorrhoea diagnoses in GP make up between 5\% and $8 \%$ of total diagnoses made in England and the downward trend in diagnosis rates broadly reflects that seen in GUM clinics during the study period. This suggests there has been minimal change in gonorrhoea testing practice in GP and that diagnoses mostly follow 
symptomatic presentations. In recent years, dual (chlamydia/gonorrhoea) nucleic acid amplification tests (NAATs) are being increasingly used for screening in a variety of clinical settings. ${ }^{34}$ Despite their convenience and increased sensitivity, positive predictive values of these tests are usually low for gonorrhoea, and confirmatory testing is strongly recommended..$^{35}$ National guidelines only recommend asymptomatic gonorrhoea screening by GPs in high-prevalence areas, and due to the complexities of management, referral of confirmed cases to GUM is strongly recommended. ${ }^{35} 36$ Our study suggests that under two-thirds of patients diagnosed with gonorrhoea in GP were referred. If non-attendance following referral is a risk, uncomplicated anogenital infection can be treated in GP. ${ }^{35}{ }^{36}$ However, care pathways for partner notification and test of cure should be in place, as infection may be a marker that the patient belongs to a higher risk sexual network. ${ }^{27}$

Almost $80 \%$ of chlamydia episodes in GP in 2011 were treated, reflecting the ongoing, steady increase previously reported. $^{9}{ }^{19}$ Compared with gonorrhoea, patients with chlamydia were less likely to be referred to GUM clinics for treatment and, when treated in GP, were most often prescribed the recommended regimen. ${ }^{9}{ }^{29}$ In contrast, about $40 \%$ of gonorrhoea episodes in GP were treated, reflecting a slight decline since the late 1990s. ${ }^{9}$ Of greatest concern, however, is that less than half the patients treated for gonorrhoea in GP were prescribed a recommended regimen. ${ }^{30} 31$ Current gonorrhoea treatment guidelines recommend intramuscular administration of ceftriaxone with concomitant oral azithromycin. ${ }^{30}$ Recommended antimicrobial treatments should eliminate infection in at least $95 \%$ of cases. ${ }^{37}{ }^{38}$ By 2002, $10 \%$ of tested specimens from GUM clinic patients were resistant to ciprofloxacin, ${ }^{39}$ rising to $36 \%$ in $2010 .^{40}$ Although fluoroquinolone prescribing in GP fell following the guidelines changed in 2005, it still accounted for $20 \%$ of prescriptions for gonorrhoea in 2011. In contrast, fluoroquinolone prescribing in GUM clinics has declined rapidly since 2003 and accounted for only $5 \%$ of prescriptions in $2010 .^{41}$ Overall, the most commonly prescribed non-recommended antibiotic was penicillin, to which up to $20 \%$ of gonorrhoea cases may be resistant. ${ }^{42}$ While amoxicillin/ampicillin can be used during pregnancy there was no evidence of this contributing to the high proportion of penicillin prescriptions.

\section{Limitations}

Some double counting of diagnoses of patients referred to GUM clinics is likely. We assumed that those treated in GP were not referred, which may not necessarily be the case, particularly for gonorrhoea. The proportion treated was calculated relative to the number of diagnoses. Some patients with a negative test result may have been treated presumptively and these were not included in our analyses. The number of patients who were referred to specialist services is likely to be underestimated as we did not have access to free-text information in CPRD. We were not able to assess whether partner notification was initiated or guidelines followed. Missing or miscoded medical records in CPRD may explain some non-recommended treatments.

CPRD data are submitted by a sample of GPs and, although patients are reasonably representative of the population, extrapolating numbers of rare and geographically clustered diagnoses such as gonorrhoea to provide national estimates may be subject to bias. ${ }^{3}{ }^{4}$ Diagnosis of chlamydia and gonorrhoea made outside GUM, NCSP and GP services could not be included in our analysis, but it is likely that the great majority of diagnoses were captured. ${ }^{43}$

\section{Conclusions and recommendations}

Our analysis shows that GPs make an important contribution to the diagnosis and treatment of bacterial STIs and that most patients diagnosed with chlamydia are managed appropriately and without the need for onward referral. While most patients diagnosed with gonorrhoea by GPs tended to be referred in accordance with national recommendations, significant numbers of those treated received antimicrobials no longer recommended for use. Treatment of infections with reduced susceptibility or resistance to the prescribed therapy may inadvertently facilitate onward transmission and risks infection complications. GPs may be less aware of gonorrhoea treatment guideline revisions due to the relative infrequency of cases seen.

Our study emphasises the importance of training and continuing professional development for non-specialists managing STIs, especially those which require complex management. ${ }^{36}$ Antimicrobial resistance in gonorrhoea is a global problem ${ }^{44}$ and may become an issue for chlamydia in future. ${ }^{45}$ Practitioners should be alert to the likelihood of revisions to national treatment guidelines and of treatment failure in their patients. Ongoing monitoring of diagnoses and treatment of STIs outside GUM services is essential for estimating the burden of STIs in the population and to ensure treatments remain appropriate and effective.

\section{Author affiliations}

${ }^{1}$ HIV \& STI Department, Public Health England, London, UK

${ }^{2}$ Centre for Sexual Health and HIV Research, University College London, Mortimer Market Centre, London, UK

${ }^{3}$ Division of Primary Care \& Public Health, Brighton and Sussex Medical School, University of Brighton, Brighton, UK

${ }^{4}$ Kent Surrey and Sussex Public Health England Centre. County Hall North. Chart Way, Horsham, West Sussex, UK

Acknowledgements The authors are grateful to CPRD staff at the Medicines and Healthcare Products Regulatory Agency for providing the data for the analysis and advice, and the practices that contribute to the CPRD.

Contributors GH, JAC, CHM and MY conceived the design of the study. SW and HM performed data management and analysis. HM, SW and GH wrote the manuscript; all authors reviewed and provided critical feedback on early drafts.

Funding This research received no specific grant from any funding agency in the public, commercial or not-for-profit sectors. 
Competing interests None.

Provenance and peer review Not commissioned; externally peer reviewed.

Data sharing statement No additional data are available.

Open Access This is an Open Access article distributed in accordance with the Creative Commons Attribution Non Commercial (CC BY-NC 4.0) license, which permits others to distribute, remix, adapt, build upon this work noncommercially, and license their derivative works on different terms, provided the original work is properly cited and the use is non-commercial. See: http:// creativecommons.org/licenses/by-nc/4.0/

\section{REFERENCES}

1. Public Health England. Table 8: Number and rates of selected ST diagnoses in the UK, 2008-2012. https://www.gov.uk/government/ statistics/sexually-transmitted-infections-stis-annual-data-tables (accessed 1 Sep 2014).

2. Sonnenberg P, Clifton S, Beddows S, et al. Prevalence, risk factors, and uptake of interventions for sexually transmitted infections in Britain: findings from the National Surveys of Sexual Attitudes and Lifestyles (Natsal). Lancet 2013;382:1795-806.

3. Le Polain De Waroux O, Harris RJ, Hughes G, et al. The epidemiology of gonorrhoea in London: a Bayesian spatial modelling approach. Epidemiol Infect 2014;142:211-20.

4. Risley CL, Ward H, Choudhury B, et al. Geographical and demographic clustering of gonorrhoea in London. Sex Transm Infect 2007:83:481-7.

5. Chisholm SA, Neal TJ, Alawattegama AB, et al. Emergence of high-level azithromycin resistance in Neisseria gonorrhoeae in England and Wales. J Antimicrob Chemother 2009;64:353-8.

6. Ison CA, Town K, Obi C, et al. Decreased susceptibility to cephalosporins among gonococci: data from the Gonococcal Resistance to Antimicrobials Surveillance Programme (GRASP) in England and Wales, 2007-2011. Lancet Infect Dis 2013;13:762-8.

7. Farley TA, Cohen DA, Elkins W. Asymptomatic sexually transmitted diseases: the case for screening. Prev Med 2003;36:502-9.

8. Simms I, Stephenson JM. Pelvic inflammatory disease epidemiology: what do we know and what do we need to know? Sex Transm Infect 2000;76:80-7.

9. Cassell JA, Mercer CH, Sutcliffe L, et al. Trends in sexually transmitted infections in general practice 1990-2000: population based study using data from the UK general practice research database. BMJ 2006;332:332-4.

10. Department of Health. Better prevention, better services, better sexual health-the national strategy for sexual health and HIV. Published 27 Jul 2001. http://webarchive.nationalarchives.gov.uk/ 20130107105354/http:/www.dh.gov.uk/en/Publicationsandstatistics/ Publications/PublicationsPolicyAndGuidance/DH_4003133 (accessed 13 Oct 2014).

11. Yung M, Denholm R, Peake J, et al. Distribution and characteristics of sexual health service provision in primary and community care in England. Int J STD AIDS 2010;21:650-2.

12. LaMontagne DS, Fenton KA, Randall S, et al. Establishing the National Chlamydia Screening Programme in England: results from the first full year of screening. Sex Transm Infect 2004;80:335-41.

13. Public Health England. Table 1: STI diagnoses \& rates in England by gender, 2004-2013. https://www.gov.uk/government/statistics/ sexually-transmitted-infections-stis-annual-data-tables (accessed 1 Sep 2014).

14. Cassell JA, Brook MG, Mercer $\mathrm{CH}$, et al. Treating sexually transmitted infections in primary care: a missed opportunity? Sex Transm Infect 2003;79:134-6.

15. Mercer $\mathrm{CH}$, Sutcliffe L, Johnson AM, et al. How much do delayed healthcare seeking, delayed care provision, and diversion from primary care contribute to the transmission of STIs? Sex Transm Infect 2007;83:400-5.

16. Neale R, Keane F, Saulsbury $N$, et al. Who attends primary care services prior to attendance at genitourinary services and what leve of care have they received? Sex Transm Infect 2008;84:233-4.

17. Sexual Health and HIV. Standards for the management of sexually transmitted infections (STIs). Published 10 Jan 2014. http://www. medfash.org.uk/standards-for-the-management-of-stis (accessed 13 Oct 2014).

18. National Chlamydia Screening Programme Standards. 7th edn. Published May 2014. http://www.chlamydiascreening.nhs.uk/ps/ standards.asp (accessed 13 Oct 2014).

19. Hughes $\mathrm{G}$, Williams $\mathrm{T}$, Simms I, et al. Use of a primary care database to determine trends in genital chlamydia testing, diagnostic episodes and management in UK general practice, 1990-2004 Sex Transm Infect 2007:83:310-13.

20. Williams $\mathrm{T}$, Van Staa T, Puri S, et al. Recent advances in the utility and use of the General Practice Research Database as an example of a UK Primary Care Data resource. Ther Adv Drug Saf 2012;3:89-99.

21. Garcia Rodriguez LA, Perez GS. Use of the UK General Practice Research Database for pharmacoepidemiology. Br J Clin Pharmacol 1998;45:419-25.

22. Herrett E, Thomas SL, Schoonen WM, et al. Validation and validity of diagnoses in the General Practice Research Database: a systematic review. Br J Clin Pharmacol 2010;69:4-14.

23. Lawson $\mathrm{DH}$, Sherman V, Hollowell J. The general practice research database. Scientific and Ethical Advisory Group. QJM 1998:91:445-52.

24. Walley T, Mantgani A. The UK general practice research database. Lancet 1997;350:1097-9.

25. Savage $\mathrm{E}$, Mohammed H, Leong G, et al. Improving surveillance of sexually transmitted infections using mandatory electronic clinical reporting: the genitourinary medicine clinic activity dataset, England, 2009 to 2013. Euro Surveill 2014;19:pii=20981.

26. Public Health England. Sexually transmitted infections (STIs): surveillance, data, screening and management. https://www.gov.uk/ government/collections/sexually-transmitted-infections-stissurveillance-data-screening-and-management (accessed $19 \mathrm{Dec}$ 2014).

27. Hughes G, Nichols T, Peters L, et al. Repeat infection with gonorrhoea in Sheffield, UK: predictable and preventable? Sex Transm Infect 2013;89:38-44.

28. Office for National Statistics. Population Estimates for UK, England and Wales, Scotland and Northern Ireland, Population Estimates Timeseries 1971 to Current Year. 2011. http://www.ons.gov.uk/ons/ $\mathrm{rel} / \mathrm{pop}$-estimate/population-estimates-for-uk-england-and-walesscotland-and-northern-ireland/population-estimates-timeseries-1971to-current-year/indexhtml (accessed 1 Apr 2013).

29. British Association for Sexual Health and HIV. 2006 UK National Guideline for the Management of Genital Tract Infection with Chlamydia trachomatis. http://www.bashh.org/documents/65.pdf (accessed 22 Dec 2014)

30. Bignell C, FitzGerald M; Guideline Development Group; British Association for Sexual Health and HIV. UK national guideline for the management of gonorrhoea in adults, 2011. Int J STD AIDS 2011;22:541-7. http://www.bashh.org/documents/3920.pdf (accessed 22 Dec 2014).

31. British Association for Sexual Health and HIV. National Guideline on the Diagnosis and Treatment of Gonorrhoea in Adults. 2005. http://www.bashh.org/documents/116/116.pdf (accessed 23 Dec 2014)

32. Public Health England. Sexually transmitted infections and chlamydia screening in England. 2013. https://www.gov.uk/ government/uploads/system/uploads/attachment_data/file/345181/ Volume_8_number_24_hpr2414_AA_stis.pdf (accessed 19 Dec 2014).

33. Department of Health. Public Health Outcomes Framework 2013 to 2016. 2012. https://www.gov.uk/government/publications/healthylives-healthy-people-improving-outcomes-and-supportingtransparency (accessed 19 Dec 2014).

34. Public Health England. Use of dual nucleic acid amplification tests (NAATs) for chlamydia and gonorrhoea. https://www.gov.uk/ government/publications/use-of-dual-nucleic-acid-amplification-testsnaats-for-chlamydia-and-gonorrhoea (accessed 1 Nov 2014).

35. Public Health England. Guidance for the detection of gonorrhoea in England. 2014. https://www.gov.uk/government/publications/ guidance-for-the-detection-of-gonorrhoea-in-england (accessed 1 Nov 2014).

36. Royal College of General Practitioners Sex DHaVHG, British Association for Sexual Health and HIV. Sexually Transmitted Infections in Primary Care 2013 (RCGP/BASHH). Lazaro N. www. rcgp.org and www.bashh.org/guidelines (accessed 1 Nov 2014).

37. FitzGerald M, Bedford C. National standards for the management of gonorrhoea. Int J STD AIDS 1996;7:298-300.

38. World Health Organisation. WHO global strategy for containment of antimicrobial resistance. http://www.who.int/drugresistance/ WHO Global Strategy_English.pdf (accessed 19 Dec 2014).

39. GRASP Steering Group. The Gonococcal Resistance to Antimicrobials Surveillance Programme Year 2002 Report. London, 2003. http:// webarchive.nationalarchives.gov.uk/20140714084352/http://www.hpa org.uk/Publications/InfectiousDiseases/HIVAndSTIs/GRASPReports/ 0201GRASP2002/ (accessed 1 Nov 2014).

40. GRASP Steering Group. The Gonococcal Resistance to Antimicrobials Surveillance Programme Year 2008 Report. 2009. 
41. Public Health England. GRASP 2011 report: The Gonococcal Resistance to Antimicrobials Surveillance Programme. http:// webarchive.nationalarchives.gov.uk/20140714084352/http://www. hpa.org.uk/Publications/InfectiousDiseases/HIVAndSTIs/ GRASPReports/1209GRASP2011/ (accessed 1 Nov 2014).

42. Public Health England. GRASP 2010 report: The Gonococcal Resistance to Antimicrobials Surveillance Programme. http:// webarchive.nationalarchives.gov.uk/20140714084352/ http://www. hpa.org.uk/Publications/InfectiousDiseases/HIVAndSTIs/ GRASPReports/1109GRASP2010/(accessed 1 Nov 2014).

43. Health Protection Agency. Testing Times-HIV and other Sexually Transmitted Infections in the United Kingdom. 2007. http:// webarchive.nationalarchives.gov.uk/20140714084352/http://www. hpa.org.uk/web/HPAweb\&HPAwebStandard/HPAweb_C/ 1203084355941 (accessed 19 Dec 2014).

44. World Health Organisation. Emergence of multi-drug-resistant Neisseria gonorrhoeae-threat of global rise in untreatable sexually transmitted infections. 2011. http://www.who.int/ reproductivehealth/publications/rtis/who_rhr_11_14/en/ (accessed 19 Dec 2014).

45. Horner PJ. Azithromycin antimicrobial resistance and genital Chlamydia trachomatis infection: duration of therapy may be the key to improving efficacy. Sex Transm Infect 2012;88: 154-6. 